\title{
Dallas MegaShelter Medical Operations Response to Hurricane Harvey
}

\author{
E. Liang Liu, MD; Brandon Morshedi, MD; Brian L. Miller, MD; Ronna Miller, MD; \\ S. Marshal Isaacs, MD; Raymond L. Fowler, MD; Wendy Chung, MD, MS; Ruby Blum; \\ Breanne Ward, BSN, RN, CEN; John Carlo, MD; Halim Hennes, MD; Frank Webster, MD; \\ Trish Perl, MD; Chris Noah, MS; Rob Monaghan, HEM; Andrew H. Tran, EMT-B, MSII; \\ Fern Benitez, MD; Julie Graves, MD, MPH, PhD; Caitlin Kibbey, MD; Kelly R. Klein, MD; \\ Raymond E. Swienton, MD
}

\section{ABSTRACT}

On August 25, 2017, Hurricane Harvey made landfall near Corpus Christi, Texas. The ensuing unprecedented flooding throughout the Texas coastal region affected millions of individuals. ${ }^{1}$ The statewide response in Texas included the sheltering of thousands of individuals at considerable distances from their homes. The Dallas area established large-scale general population sheltering as the number of evacuees to the area began to amass. Historically, the Dallas area is one familiar with "mega-sheltering," beginning with the response to Hurricane Katrina in $2005 .^{2}$ Through continued efforts and development, the Dallas area had been readying a plan for the largest general population shelter in Texas. (Disaster Med Public Health Preparedness. 2019;13:90-93)

Key Words: Hurricane Harvey, Disaster Planning, MegaShelter

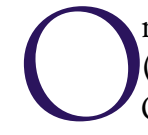
August 29, 2017, the Dallas MegaShelter (DMS) opened at the Kay Bailey Hutchison Convention Center in Dallas prepared to shelter up to 5000 Hurricane Harvey evacuees (Figure 1). ${ }^{3}$ Throughout Texas, tens of thousands sought refuge in many locations, including large and small shelters. An important component of large-scale sheltering is the provision of timely, accessible, and affordable medical services. In support of quality sheltering operations, the DMS concept utilized on-site provision of these services known as the MegaShelter Medical Clinic (MMC), an integral part of the overall DMS operational plan.

\section{THE MEGASHELTER MEDICAL CLINIC}

With nearly half of the US population having chronic medical conditions or functional needs, morbidity and mortality rise during disasters. ${ }^{4}$ Part of the initial planning in Texas since 2006 for large-scale sheltering has included accommodating the functional and medical needs of at-risk populations. Forty-eight hours before the opening of the DMS, the MMC task force was activated by the Dallas Office of Emergency Management. The long-term strategic alliances and collaborative partnerships among federal, state, regional, and local assets facilitated the timely opening of the MMC within the DMS (Figure 2).

The provision of accessible, affordable, and essential health services to a displaced population is mission critical. Simply directing a displaced population to "self-seek" such services in an unfamiliar community with limited personal means is unacceptable. Since 2005, multiple experiences serving displaced populations have demonstrated multiple service needs (Table 1).

\section{Clinic Structure}

Leaning on the past 12 years of operational experience and continual preparedness, modeling for the MMC had a solid foundation. Guidance and compliance considerations from source documents, as well as established policies and procedures, were utilized. ${ }^{5}$

The base of general sheltering including the MMC was housed in a climate-controlled parking facility of approximately 200,000 square feet. The MMC itself occupied approximately 13,000 square feet of this area. The area was divided into multiple clinical and adjunct health services areas as listed in Table 2 .

The MMC incident command reporting structure was integrated into overall emergency management governance. Liaisons from each health service area in Table 2 and other DMS service providers (County Judge's Office, American Red Cross, Texas State Guard, National Guard, Dallas County Medical Society, Dallas County Health and Human Services, Medical Reserve Corps, etc) were included. Adaptations to the incident command structure were necessary to maintain appropriate span of control and 


\section{FIGURE 1}

\section{Dallas MegaShelter (DMS) Opened at the Kay Bailey Hutchison Convention Center.}

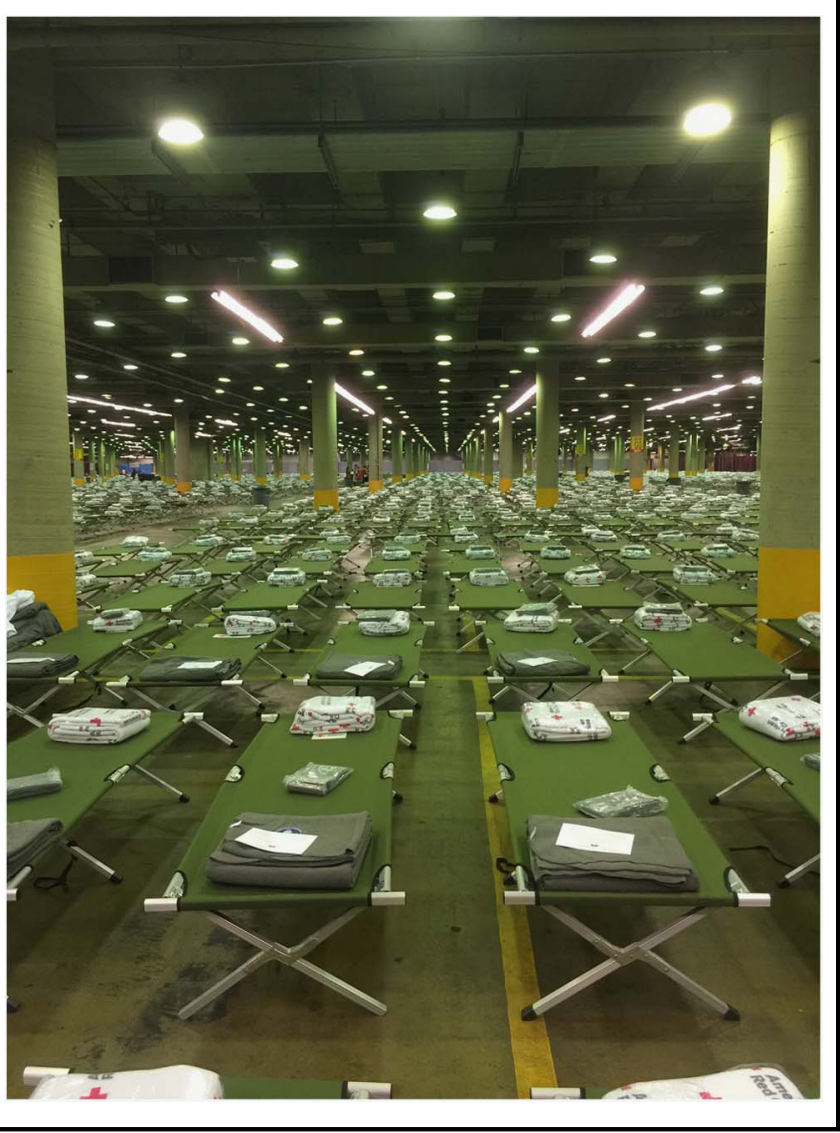

\section{FIGURE 2}

\section{MegaShelter Medical Clinic Entrance.}

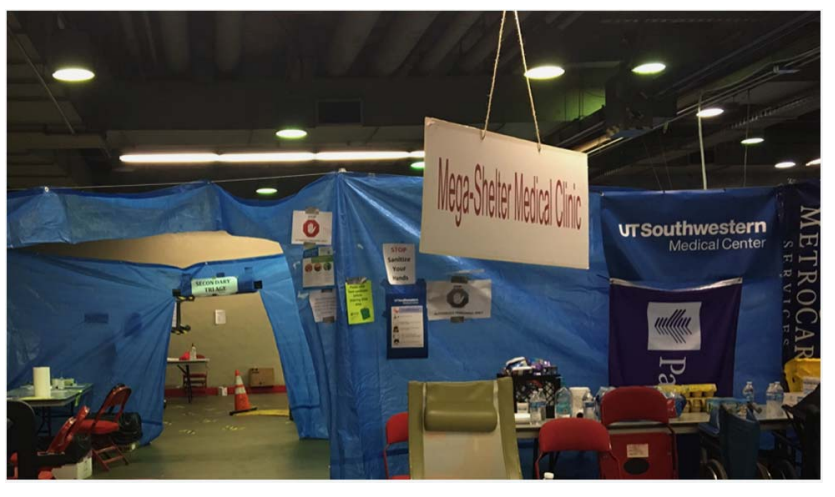

to align with partnering agencies. Daily incident command briefings and metrics reporting provided timely situational awareness and identification of unmet needs and resource utilization. Just-in-time protocols and clinical pathways supported seamless integration among a variety of multidisciplinary health professionals.

\section{TABLE}

\section{Health and Medical Services Provided During Shelter Operations}

\section{Health and Medical Services}

1. Emergent, acute, and observational clinical screening and basic treatment

2. Pharmaceuticals for disease management and provision of over-the-counter medications

3. Select subspecialty clinical services (pediatrics, behavioral health, infectious disease, etc)

4. Coordination, transportation, and access to scheduled community clinical services

5. Identifying and coordinating access to dialysis resources

6. Surveillance and direct public health shelter oversight of infectious diseases

7. Provision of essential durable medical equipment

8. Supporting shelter operations for those with functional needs

9. Surveillance and intervention for mental health needs

10. Essential laboratory services

\section{TABLE 2}

\section{Health and Medical Service Areas in the MegaShelter Medical Clinic}

\section{Health and Medical Service Areas}

1. Medical command office

2. Triage and registration

3. Acute and emergent care

4. Emergency medical services (EMS) screening and transportation staging area

5. Nonacute clinical service pods $(n=4)$

6. Pediatric clinic and telehealth

7. Mental health

8. Public health

9. Pharmacy

10. Observation unit

11. Isolation unit

12. Health information management

\section{Operations}

Initially, coastal evacuees arrived at the DMS via personal vehicles. Subsequently, over multiple days, evacuees arrived at the DMS via statewide airlift (arrivals of C-130 Department of Defense aircraft) and convoys of arriving buses. Cumulatively, the total shelter registered guests exceeded 3800 .

Over the span of 23 days of continuous operation, the MMC provided medical management to over 2500 shelter evacuee patients. Approximately 140 patients were transported by emergency medical services to area emergency departments. The admission rate to the hospital of those transported was approximately $20 \%$, with no reported deaths. Admission diagnoses included acute myocardial infarction, status epilepticus, altered mental status, acute substance misuse, 
Timeline of Events for MegaShelter Medical Clinic, Dallas, Texas, August 25 Through September 20, 2017.

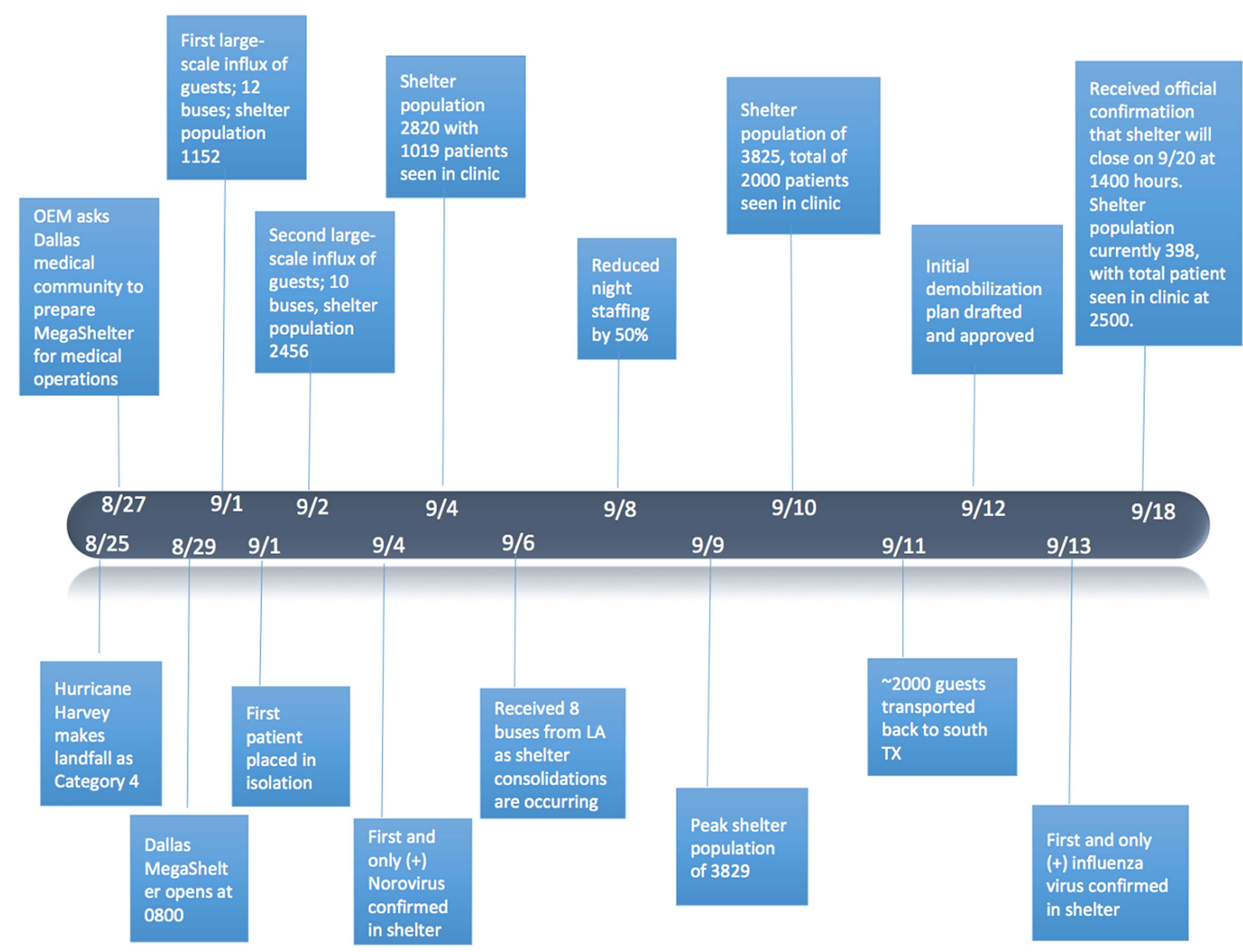

pediatric severe asthma, and acute exacerbations of chronic disease.

At peak of operations nearly 300 patients were evaluated daily by the MMC, with an average census exceeding 100 patients per day. Early sustained patient volumes approached the average daily patient volumes reported by some of the busiest hospitals in the United States. ${ }^{6}$ The Most common complaints included medication refills, vomiting and diarrhea, fever, skin rashes, pharyngitis, upper respiratory congestion, minor injuries, conjunctivitis, and intoxication. Monitoring patients with chronic end-stage renal disease required laboratory-guided treatment and dialysis services routinely coordinated by the MMC and shelter shuttle services. The isolation area observed 29 persons under public health surveillance, successfully preventing any widespread outbreak of illness development within the shelter, as reflected in the overall MMC timeline seen in Figure 3.

\section{DISCUSSION}

The provision of these health and medical services in the altered care environment of a large-scale general population shelter within a convention center climate-controlled parking facility permitted the delivery of timely, accessible, and affordable care. Indeed, all health and medical services were provided free of charge to registered evacuees.

Mission objectives were defined that guided daily operations of the MMC. The most important was the safety of the patient population and the service providers. Credentialed medical staff members were provided operational guidelines to standardize resource utilization, assure patient safety, and provide the highest quality care. Public health surveillance throughout the shelter and preventative measures to reduce infectious disease spread were continuously maintained. Contagious disease screening was completed on every presenting patient at the triage area. When indicated, a patient with concerning signs and symptoms was taken directly to the isolation area overseen by infectious disease and public health specialists for evaluation and management.

The local Dallas health care system contributed 24-hour volunteer staff to provide medical services. Public, private, and corporate donations of pharmaceuticals, durable medical equipment, and laboratory capabilities were essential to 
the operation. Multiple health facilities provided free scheduled appointments for the evacuees, with transportation provided.

"It is a marathon, not a sprint" became the mantra of MMC incident command leadership. They recognized early the importance of sustainable performance through team building, clinical schedule management, recognition of service excellence, and just-in-time process improvement. These acknowledgments significantly contributed to important successes, including that there were no deaths during the medical operations, no untoward outcomes, and a strong maintenance of volunteer energy and dedication.

\section{AFTER ACTION PREVIEW}

The MMC closed operations at 1100 hours on 20 September 2017. The experience highlights many issues that will impact future planning (Table 3). The breadth of the medical services required by the evacuees presented unique challenges. Sheltering evacuees for multiple weeks brings the need for expanded health services such as chemotherapy for established cancer treatments. In some circumstances, subspecialty and therapeutic services were available but access to them was limited by timely coordination. Focus will be to expand local partnerships addressing areas such as dental, vision, chronic pain management, chronic wound care, physical therapy, etc.

\section{TABLE 3}

\section{Opportunities to Improve the MegaShelter Medical Clinic $^{\mathrm{a}}$}

\section{Opportunities to Improve}

1. Expanded access for clinical and subspecialty care beyond the MMC capabilities

2. Coordination of transportation of shelter residents for outpatient medical needs

3. Improve intake education and training for evacuees on infection control measures

4. Vast amounts of donations require better inventory control and utilization

5. Create a central repository of credentialed, resource-typed volunteers and availability

6. Coordinate external health and medical resources, specialty clinic access, and linkage

7. Streamline process for office supplies, nonmedical equipment, and procurement

8. Earlier and expanded social services and case management

9. Health information management, electronic health records, and medical record access

10. Expand opportunities for health professions students

${ }^{a}$ Abbreviation: MMC, MegaShelter Medical Clinic.
In response to this disaster, the $\mathrm{MMC}$ received an outpouring of generosity in the form of both corporate and nonprofit outreach and individual donations. Reaching out to those who did with great appreciation is important. Recognizing the City of Dallas, Dallas County, and the support and guidance of the involved civic leaders was critical to this successful operation. The input and on-site assistance of state and federal agencies was invaluable throughout the experience. The MMC has been an amazing opportunity to step past tabletop exercises and learn through just-in-time training and innovative problem-solving to address the needs and concerns faced in large-scale general population sheltering.

\section{About the Authors}

Department of Emergency Medicine, University of Texas Southwestern Medical Center, Dallas, Texas (Drs Liu, Morshedi, B Miller, R Miller, Isaacs, Fowler, Benitez, Graves Kibbey, Klein, and Swienton); Dallas County Health and Human Services, Dallas, Texas (Dr Chung); Office of the Dallas County Judge, Dallas, Texas (Ms Blum); Dallas County Emergency Nurses Association, Dallas, Texas (Ms Ward); Dallas County Medical Society, Dallas, Texas (Dr Carlo); Department of Pediatrics, University of Texas Southwestern Medical Center, Dallas, Texas (Dr Hennes); Emergency Psychiatric Medicine, LLC, Dallas, Texas (Dr Webster); Division of Infectious Diseases, University of Texas Southwestern Medical Center, Dallas, Texas (Dr Perl); Parkland Health and Hospital Systems, Dallas, Texas (Mr Noah); Baylor Scott $\mathcal{E}$ White Health, Dallas, Texas ( $\mathrm{Mr}$ Monaghan); School of Medicine, University of Texas Southwestern Medical Center, Dallas, Texas (Mr Tran).

Correspondence and reprint requests to Raymond E. Swienton, MD, Department of Emergency Medicine, University of Texas Southwestern Medical Center, Dallas, Texas (email: beardogmd@aol.com).

\section{REFERENCES}

1. Gomez L. Hurricane Harvey: 50 counties flooded, 30,000 people in shelters, 56,000 911 calls in just 15 hours. San Diego Union Tribune. http:// www.sandiegouniontribune.com/opinion/the-conversation/sd-hurricaneharvey-texas-flooding-displaces-thousands-20170828-htmlstory.html. Published Aug 28, 2017. Accessed September 25, 2017.

2. Eastman AL, Rinnert KJ, Nemeth IR, et al. Alternate site surge capacity in times of public health disaster maintains trauma center and emergency department integrity: Hurricane Katrina. J Trauma. 2007;63(2):253-257.

3. McLaughlin E, Ellis R, Sterling J. Dallas preps 'mega-shelter' as Texas braces for more rain. CNN. http://www.cnn.com/2017/08/27/us/harvey-landfall/ index.html. Published August 28, 2017. Accessed September 25, 2017.

4. Mace SE, Doyle CJ. Patients with access and functional needs in a disaster. South Med J. 2017;110(8):509-515. doi: 10.14423/SMJ. 0000000000000679.

5. FEMA. Guidance on Planning for Integration of Functional Needs Support Services in General Population Shelters. https://www.fema.gov/ pdf/about/odic/fnss_guidance.pdf Published November 2010. Accessed September 25, 2017.

6. Dietsche E. 52 hospitals with the most ER visits. Beckers Hospital Review. http://www.beckershospitalreview.com/lists/50-hospitals-with-the-most-ervisits-2016.html. Published Mar 17, 2016. Accessed September 25, 2017. 